\title{
AN ANALYSIS OF LAND USE AND LAND COVER DYNAMICS AND CAUSATIVE DRIVERS IN A THICKLY POPULATED YAMUNA RIVER BASIN OF INDIA
}

\author{
BANSAL, S. $^{1 *}$-SRIVASTAV, S. K. ${ }^{1}-$ ROY, P. S. ${ }^{2}-$ KRISHNAMURTHY, Y. V. N. ${ }^{3}$ \\ ${ }^{I}$ Indian Institute of Remote Sensing, Indian Space Research Organisation, \\ 4-Kalidas Road, Dehradun 248001, India \\ (email: sksrivastav@iirs.gov.in) \\ ${ }^{2}$ National Academy of Sciences, University of Hyderabad, \\ Prof. C.R. Rao Road, Gachibowli, Hyderabad 500046, India \\ (email:psroy13@gmail.com) \\ ${ }^{3}$ Indian Space Research Organisation, ISRO Headquarters, \\ Antariksh Bhavan, New BEL Road, Bangalore 560231, India \\ (email: yvnkrishna@ rediffmail.com) \\ *Corresponding author \\ email:sari.bansal@gmail.com or sari14.bansal@gmail.com \\ (phone: +91-9720906816) \\ (Received $31^{\text {st }}$ May 2016; accepted $28^{\text {th }}$ Jun 2016)
}

\begin{abstract}
Understanding the land use and land cover (LULC) change processes is of great importance for formulating the land use policy. In the present study, Remote Sensing, Geographic Information System (GIS) and statistical techniques are used to understand the LULC dynamics and possible driving forces in a thickly populated Yamuna river basin of India. The National Capital Territory of Delhi, one of the world's largest urban agglomerations, occurs in this river basin. The LULC maps on 1:250,000 scales prepared at decadal interval $(1985,1995$ and 2005) using satellite images are used for studying the LULC dynamics. The major LULC changes observed during the study period are increase in cropland $(65.7 \%$ to $67.9 \%)$ and built-up $(0.9 \%$ to $1.9 \%)$ and decrease in forest $(17.1 \%$ to $16.4 \%)$ and water bodies $(2.3 \%$ to $1.9 \%$ ). The dominant processes of the LULC changes include transitions from forest, grassland, shrub land, water bodies and wasteland to cropland; transitions from cropland, shrub land, wasteland, grassland and forest to built-up; conversion of forest to cropland, shrub land, plantation and built-up; and transitions from water bodies to cropland, shrub land and wasteland. Most of the transitions are reversible in nature. The statistical analysis (logistic regression) between decadal LULC maps and drivers indicates that LULC changes are driven by a multitude of factors in different combinations and with different importance. Socioeconomic, demographic and proximity drivers mainly influence the LULC change processes in the study area in decreasing order of importance. The insights gained are important for simulating future LULC scenarios as input for land management policy making.
\end{abstract}

Keywords: land use and land cover (LULC); remote sensing; geographic information system; logistic regression; drivers of LULC change; Yamuna basin

\section{Introduction}

Land is the most valuable natural resource that has been transforming since ages to meet the demands of human kind in pursuit of better life. Some of the major landscapes changes across the world have arisen due to human interference (Viles and Goudie, 1997; Lambin et al., 2001). A strong trend of urban development can be observed throughout the world (United Nations Centre for Human Settlements, 1996) and India is no exception, which has witnessed phenomenal development in different sectors since 
independence. It occupies $2.3 \%$ of the world's land area and supports more than $17.5 \%$ of the world's population. Indian agriculture has grown at the rate of about $2.6 \%$ per annum in the post-independence era which is double the rate of pre-independence era (Tripathi and Prasad, 2010). Significant land use and land cover (LULC) changes have occurred in the country during the last few decades wherein demography, rapid development, urbanisation and agriculture expansion has exerted an increasing pressure on land. Historically, it has been observed that most of the developed cities in India are located near the river banks. Considering this fact, the present study lays emphasis on understanding the interaction of causative driving forces and LULC change in Yamuna river basin of India.

The Yamuna is the longest tributary of river Ganga in the Lower Himalaya. After flowing for about $200 \mathrm{~km}$ in the Himalaya, it then emerges into the Indo-Gangetic plains (Rai et al., 2012) where it flows almost parallel to river Ganga and ultimately meets river Ganga at Allahabad in the state of Uttar Pradesh. While flowing in IndoGangetic plains, it creates a large $\left(\sim 69,000 \mathrm{~km}^{2}\right)$ fertile zone called Ganga-Yamuna Doab. The drainage basin is highly vegetated and populated area that needs attention towards LULC change analysis. The study area covers part of seven states of the country namely, Uttar Pradesh, Himachal Pradesh, Madhya Pradesh, Uttarakhand, Haryana, Rajasthan and National Capital Territory of Delhi. It is thickly populated with highest population density in Delhi. Yamuna waters feed a large population and are the source of irrigation. Studying LULC change processes and understanding their linkages with socioeconomic, demographic and physical factors are thus critical for formulating land use policy in this river basin.

The driving factors responsible for LULC change in an area may be socioeconomic, demographic, physical, proximate or a combination of all these. Also, these driving factors may operate independently at different levels in a simultaneous manner that may vary in time and space (Geist and Lambin, 2002). The changing patterns of LULC and their driving factors have been studied in different countries at various scales. In India, the changing patterns of LULC with decrease in forest cover, expansion of cropland and increase in built-up areas have been identified from 1880 to 2010 (Tian et al., 2014). Recently, in another study on LULC changes in India (Roy et al., 2015), significant increase in built-up areas and cropland and decrease in fallow land, forest and wasteland have been identified during 1985 to 2005 using satellite images. In a similar study in Northeast China (Shen et al., 2013), changes in built-up, cropland, forest, grassland and wetland were analysed from 1970 to 2004 that highlighted the effectiveness of forest and wetland protection and restoration projects. Decrease in ecosystem services value were found in Su-Xi-Chang region of Yangtz river delta, East China, due to the loss of cropland and water bodies by urban expansion (Yirsaw et al., 2016). In Bonsa catchment of Ankora river basin in Ghana, West Africa, land cover transitions from 1986 to 2011 showed that increase in population growth, agriculture expansion and increased surface mining activities were responsible for increased deforestation rate (Aduah, 2014). In Poland, the effect of LULC on ecological quality of rivers were analysed which showed decline in population of bryophytes due to the loss of forest (Zgola, 2014). Human induced LULC changes were revealed in Kagera Basin of Lake Victoria (Wasige et al., 2013). Role of socioeconomic and physical drivers on land degradation were identified in Vietnam (Vu et al., 2014).

It is difficult to link the drivers of LULC change in a heterogeneous landscape because of uncertainty associated with misclassification and availability of data at 
diverse scales (Martinez et al., 2011). LULC change is dynamic in nature and it is difficult to obtain the real time information of LULC change through conventional methods. Satellite remote sensing along with GIS that can bring different types of data at one platform for analysis has brought a new dimension to study LULC changes at varied scales (Wang et al., 2013).

In the present study, we investigate LULC change processes and the possible driving forces of such change in the Yamuna river basin of India using remote sensing, GIS and statistical techniques.

\section{Materials and Methods}

\section{Study Area}

Yamuna River originates from Yamunotri glacier at $30.98^{\circ}$ and $78.45^{\circ}$ in the Mussoorie range of the Lower Himalaya in the state of Uttarakhand, India. It covers an area of $3,66,223 \mathrm{~km}^{2}$ which is about $42.5 \%$ of the total area of Ganga basin and $10.7 \%$ of the total country's land area. In the present study, the drainage area of Chambal river, which is a major tributary of river Yamuna, has been excluded. The study area of Yamuna basin $\left(\sim 1,98,890 \mathrm{~km}^{2}\right)$ delineated from $90 \mathrm{~m}$ digital elevation model (DEM) obtained from Shuttle Radar Topography Mission (SRTM) as shown in Fig.1. Tons, Chambal, Hindon, Sind, Betwa, Ken, Baghein and Mandakini are major tributaries and Rishi Ganga, Uma, Hanuman Ganga, Giri, Karan, Sagar and Rind are smaller tributaries of Yamuna. The basin landscape is characterized by hills, valleys, plains, lakes and network of river streams. Many protected areas like sanctuaries (Bhindawas bird sanctuary, Okhla wildlife sanctuary, Hastinapur wildlife sanctuary, National Chambal wildlife sanctuary, etc.) and National parks (Ranthambore national park, Kalesar national park, Keoladeo Ghana national park) are situated in the study area. The basin has a huge variety of flora and fauna that varies with respect to the location and environment. The elevation in the basin varies from $6320 \mathrm{~m}$ above mean sea level near Yamunotri Glacier to around $100 \mathrm{~m}$ near the confluence with the river Ganga at Allahabad with highly varied topography from steep, rugged mountains in the Himalaya to almost flat in Indo-Gangetic plains. About $42 \%$ of the area is covered by alluvial soil and over $50 \%$ of the area is cultivated. The irrigated land area in the basin is about 12.3 million hectares. There are four irrigation canals in the basin namely, Western Yamuna canal, Eastern Yamuna canal, Agra canal and Gurgaon canal that delivers the Yamuna water to the command areas (Rai et al., 2012).

\section{Methodology}

The methodology includes three parts viz, LULC change analysis and accuracy assessment; preparation and integration of socioeconomic, physical, demographic and proximity driver datasets; and statistical analysis to derive relationship between drivers and LULC changes (Fig. 2). Different datasets used in the present study and their sources are listed in Table 1. 


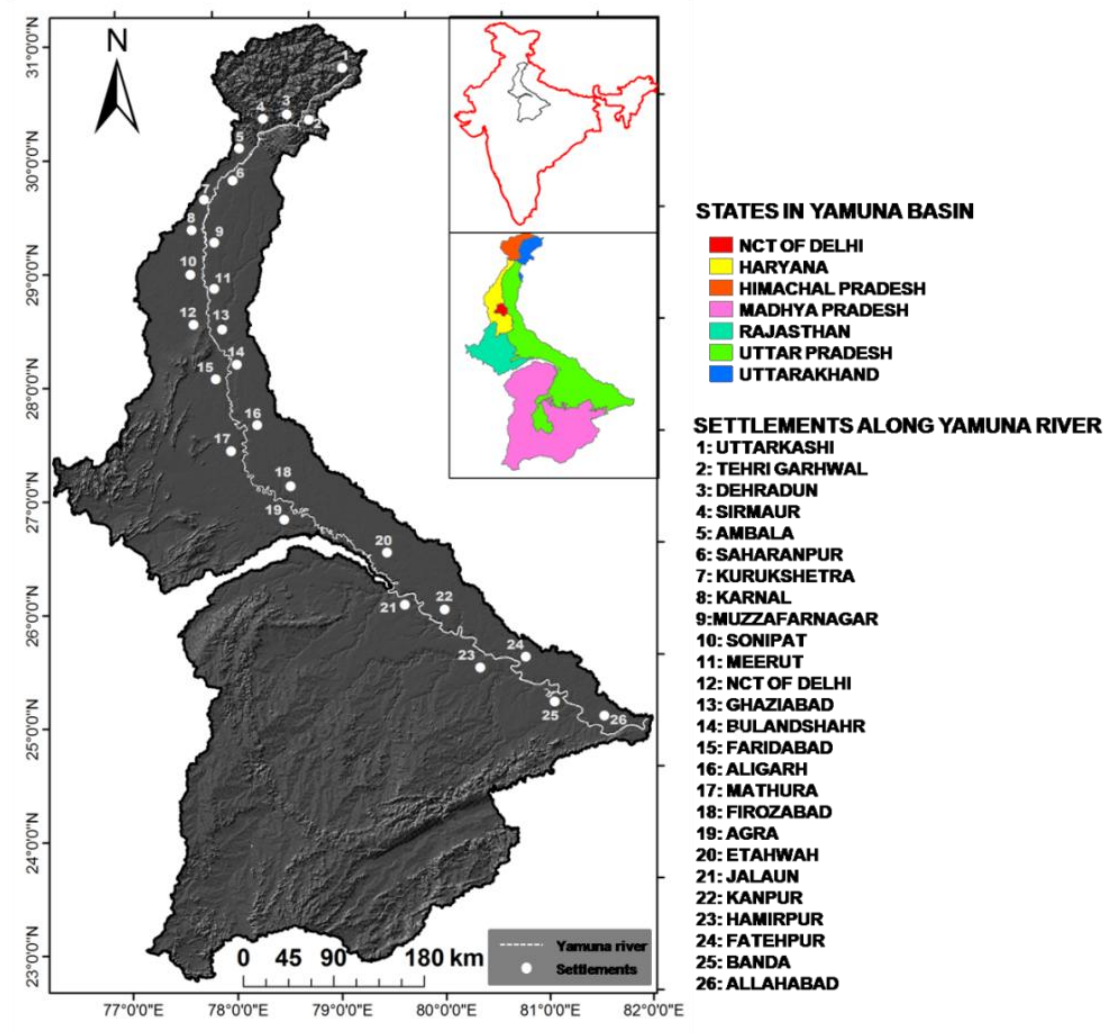

Figure 1. Study area taken for the present study

Table 1. Datasets used in the study

\begin{tabular}{|c|c|c|c|}
\hline \multicolumn{4}{|l|}{ LULC maps } \\
\hline Dataset & \multirow{2}{*}{\multicolumn{2}{|c|}{$\begin{array}{l}\text { Time period } \\
1985,1995 \text { and } 2005\end{array}$}} & Source \\
\hline LULC Maps & & & ISRO Geosphere Biosphere (GBP) Programme (Roy et al. 2015) \\
\hline \multicolumn{4}{|l|}{ Satellite data } \\
\hline Dataset & Resolution & Time period & Source \\
\hline IRS LISS-III & $23.5 \mathrm{~m}$ & 2005 & ISRO-GBP \\
\hline IRS LISS-I & $30 \mathrm{~m}$ & 1995 & ISRO-GBP \\
\hline Landsat-MSS & $56.25 \mathrm{~m}$ & 1985 & Global Land Cover Facility (GLCF) \\
\hline \multicolumn{4}{|l|}{ Physical data } \\
\hline Dataset & Resolution & Time period & Source \\
\hline Elevation & $90 \mathrm{~m}$ & 1995 and 2005 & Shuttle Radar Topography Mission (SRTM) DEM \\
\hline Slope & $90 \mathrm{~m}$ & 1995 and 2005 & SRTM DEM \\
\hline Mean annual temperature & $1^{0}$ & 1995 and 2005 & India Meteorological Department (IMD) \\
\hline Annual rainfall & $0.5^{0}$ & 1995 and 2005 & IMD \\
\hline Soil depth & $1: 1$ million & 1995 and 2005 & $\begin{array}{l}\text { Soil map of National Bureau of Soil Survey and Land use planning } \\
\text { (NBSSLUP), Nagpur }\end{array}$ \\
\hline \multicolumn{4}{|c|}{ Demographic and Socioeconomic data } \\
\hline Dataset & Scale & Time period & Source \\
\hline Total population & Taluka & 1995 and 2005 & Census of India, State Development Reports, Census handbooks, \\
\hline Total working population & District & 1995 and 2005 & Indiastat.com, Ministry of Statistics and Programme Implementation \\
\hline $\begin{array}{l}\text { Number of agriculture } \\
\text { workers }\end{array}$ & District & 1995 and 2005 & \\
\hline Road length & District & 1995 and 2005 & \\
\hline \multicolumn{4}{|l|}{ Proximity data } \\
\hline Dataset & \multicolumn{2}{|c|}{ Time period } & Source \\
\hline Distance to built-up & \multirow{3}{*}{\multicolumn{2}{|c|}{$\begin{array}{l}1995 \text { and } 2005 \\
1995 \text { and } 2005 \\
1995 \text { and } 2005\end{array}$}} & LULC maps of 1995 and 2005 \\
\hline Distance to forests & & & \\
\hline Distance to water bodies & & & \\
\hline
\end{tabular}




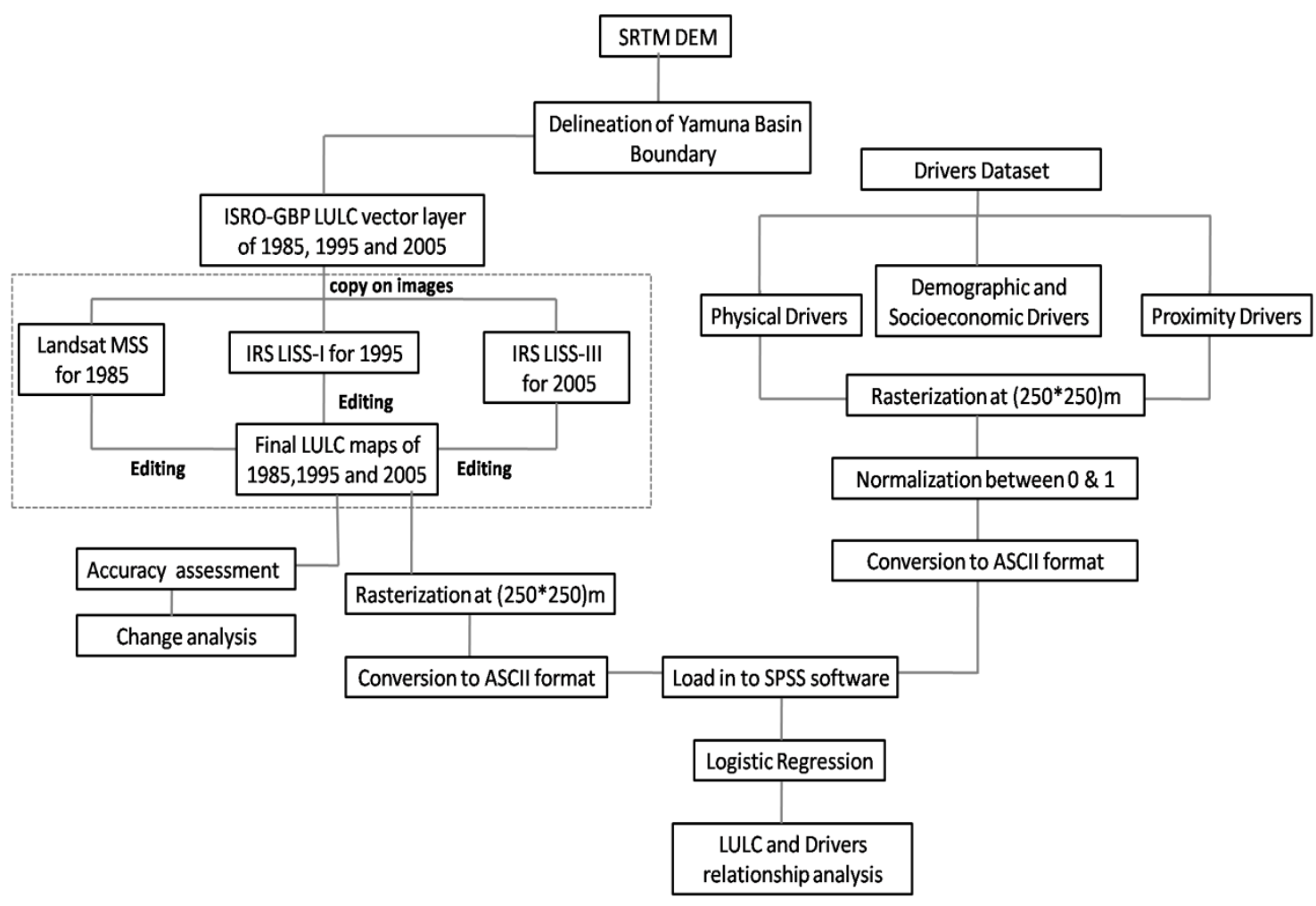

Figure 2. Methodology followed in the present study

\section{Change analysis and accuracy assessment}

Decadal LULC maps of 1985, 1995 and 2005 were prepared at 1:250,000 scales formed the basic inputs (Roy et al., 2015). The LULC maps follow IGBP (International Geosphere Biosphere Programme) LULC classification scheme (Loveland and Belward, 1997). In the present study, LULC maps were prepared by merging different types of forest classes to one forest class and cropland and fallow land to cropland class (Table 2). A total of ten LULC classes, i.e. built-up, cropland, plantation, forest, shrub land, grassland, baren land, wasteland, water bodies, permanent wetland were then refined wherever required using satellite images of Landsat-MSS, IRS LISS-I and IRS LISS-III satellite images respectively for 1985, 1995 and 2005 to produce modified LULC maps (Fig. 3). Snow and ice class was masked for the present study. Accuracy assessment is then carried out for LULC map of 2005 with aid of confusion matrix by using Google Earth as reference data. We have generated a total of 9003 random points with minimum of 3 points per polygon. From the confusion matrix, individual class accuracy, overall accuracy and kappa coefficient were computed (Congalton, 1991). The overall accuracy and kappa coefficient of 2005 LULC map is $89.82 \%$ and 0.88 , respectively (Table 3). The accuracy assessment was performed for 2005 LULC map only and assumed to be of the same order for LULC maps of 1985 and 1995 considering the mapping procedures followed in preparing decadal LULC maps (Roy et al., 2015). After the refinement of LULC maps and accuracy assessment, the change area matrices are prepared for three periods, i.e. 1985-1995, 1995-2005 and 1985-2005. These matrices were used to analyse the transition of one LULC class to other LULC class. 
Table 2. LULC classification scheme adopted in the study

\begin{tabular}{|lll|}
\hline $\begin{array}{l}\text { IGBP LULC Classes } \\
\text { (Roy et al. 2015) }\end{array}$ & $\begin{array}{l}\text { LULC Classes } \\
\text { used in study }\end{array}$ & Code \\
\hline 1.0 Built-up (both urban and rural) & 1. Built-up & BU \\
2.0 Crop Land & 2. Cropland & CL \\
2.1 Fallow land & 3. Plantation & PL \\
3.2 Plantation & 4. Forest & F \\
3.1 Evergreen needle forest & & \\
3.2 Deciduous needle forest & & \\
3.3 Deciduous broad leaf forest & & \\
3.4 Mixed forest & 5. Shrub land & SL \\
3.5 Shrub land & 6. Grassland & GL \\
3.7 Grassland & 7. Barren land & BL \\
4.0 Barren land & 8. Wasteland & WL \\
5.0 Wateland bodies & 9. Water bodies & WB \\
5.1 Permanent Wetland & 10.Permanent Wetland & PW \\
\hline
\end{tabular}
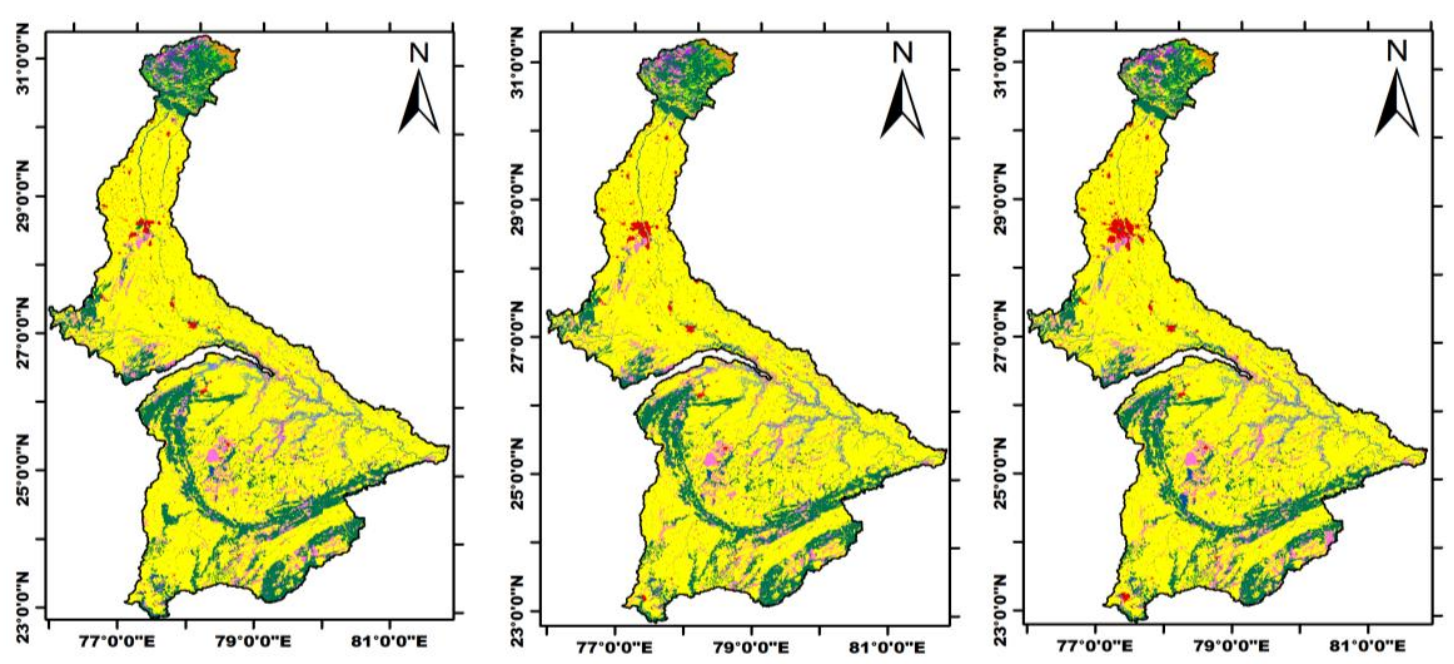

Legend

Built-up

Cropland

Plantation Forest

Shrub land

Grassland

Barren land

Wasteland

Water bodies

Permanent Wetland

Snow and Ice (masked)

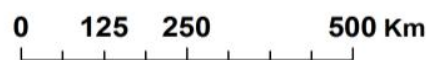

Figure 3. Decadal LULC maps: (a) 1985, (b) 1995 and (c) 2005

\section{Preparation of driver datasets}

The socioeconomic, demographic, physical and proximity driver datasets were prepared for 1995 and 2005 (Table 1). The demographic driver includes total population and socioeconomic drivers include total working population, number of agriculture workers and road length. The physical drivers include slope, mean annual temperature, annual rainfall and soil depth whereas proximity drivers include distance to built-up, distance to forests and distance to water bodies. These drivers were used as independent variables in the statistical analysis. 
Table 3. Accuracy assessment of LULC map of 2005

\begin{tabular}{|c|c|c|c|c|c|c|c|c|c|c|c|c|c|}
\hline \multirow{13}{*}{ 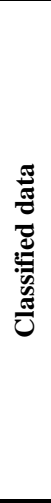 } & \multicolumn{12}{|c|}{ Reference data } & \multirow{2}{*}{$\begin{array}{c}\begin{array}{c}\text { Users } \\
\text { accuracy } \\
(\%)\end{array} \\
\end{array}$} \\
\hline & $\begin{array}{l}\text { LULC } \\
\text { Classes }\end{array}$ & BL & BU & CL & $\mathbf{F}$ & GL & PL & PW & SL & WB & WL & Total & \\
\hline & \multirow{2}{*}{$\begin{array}{l}\text { BL } \\
\text { BU }\end{array}$} & 519 & 1 & 23 & 87 & & & & 3 & \multirow[b]{2}{*}{2} & & 633 & \multirow{2}{*}{$\begin{array}{l}81.9 \\
94.4\end{array}$} \\
\hline & & 13 & 1634 & 72 & 2 & & & 1 & 7 & & & 1731 & \\
\hline & CL & & 4 & 1147 & 24 & & 1 & & 25 & \multirow[t]{2}{*}{5} & 3 & 1209 & \multirow{2}{*}{$\begin{array}{l}94.8 \\
91.9\end{array}$} \\
\hline & $\mathbf{F}$ & & 5 & 109 & 1544 & & 4 & & 18 & & 1 & 1681 & \\
\hline & GL & & 96 & 17 & 2 & 315 & 6 & & & \multicolumn{2}{|l|}{1} & 437 & \multirow{7}{*}{$\begin{array}{l}72.1 \\
96.1 \\
93.5 \\
87.2 \\
85.0 \\
89.0\end{array}$} \\
\hline & PL & & 3 & 12 & & 2 & 415 & & & & & 432 & \\
\hline & PW & & & 8 & & & & 116 & & & & 124 & \\
\hline & SL & 12 & 2 & 75 & & 46 & & & 946 & & 4 & 1085 & \\
\hline & WB & & & 116 & 6 & 10 & & & 3 & 764 & & 899 & \\
\hline & WL & 3 & 2 & 52 & 7 & 19 & & & 1 & 1 & 687 & 772 & \\
\hline & Total & 547 & 1747 & 1631 & 1672 & 392 & 426 & 117 & 1003 & 773 & 695 & 9003 & \\
\hline \multicolumn{2}{|c|}{$\begin{array}{c}\text { Producer } \\
\text { accuracy }(\%)\end{array}$} & 94.9 & 93.5 & 70.3 & 92.3 & 80.4 & 97.4 & 99.1 & 94.3 & 98.8 & \multicolumn{2}{|l|}{98.8} & \\
\hline \multicolumn{14}{|c|}{ Overall accuracy: $89.82 \%$} \\
\hline
\end{tabular}

BL- Barren land, BU- Built-up, CL- Cropland, F- Forest, GL- Grassland, PL- Plantation, PW- Permanent Wetland, SL- Shrub land,

WB- Water bodies, WL- Wasteland.

The socioeconomic data were collected at district level with the exception of population data which was collected at taluka (sub-district) level. The data set were collected from Census of India, Indiastat.com, Census handbooks, State development reports and Statistical diaries. The slope and elevation has been derived from the SRTM DEM. The annual rainfall and mean annual temperature were obtained from IMD (India Meteorological Department). The rainfall and temperature data were available at half and one degree grid, respectively. The soil depth was extracted from the soil map prepared at 1:1 million scale by National Bureau of Soil Survey and Land Use Planning, Nagpur. The soil depth was segregated from this map and reclassified and appended with the map as a new field. The proximity drivers viz., distance to built-up, distance to forests and distance to water bodies were derived from LULC maps of 1995 and 2005 using Euclidean distance in Arc GIS software. All the datasets were rasterized at $(250 \mathrm{~m} \times 250 \mathrm{~m})$ and normalized between 0 and 1 , so as to balance the range of data values (Fig. 4).

Normalization of data values is important because of the sensitivity of data transformation in statistical analysis (logistic regression in the present case). Normalization is done by dividing the value of each grid cell with the highest value of cell data to achieve similar data range. Moreover, in the multivariate analysis such as logistic regression, the independent variables should have a similar scale to avoid discrepancy in outcome (Veldkamp and Fresco, 1997; Verburg et al., 2004; Nefeslioglu et al., 2008). After normalization, the raster data were converted to ASCII files and used for statistical analysis in SPSS software.

\section{Statistical analysis between drivers and LULC change}

To analyse the relationship between LULC classes (dependent variables) and possible driving factors (independent variables), logistic regression has been used. The analysis was performed between LULC classes and drivers of 1995 and 2005, respectively. The regression was run specifically for classes which are undergoing significant changes like built-up, cropland, forest, water bodies, barren land, wasteland 
and shrub land. Since the driver datasets were prepared at coarse resolution, the regression was not performed for classes having smaller areas like permanent wetland, grassland and plantation to avoid meaningless results due to difference in scales. The total number of independent variables used to explain the spatial patterns of LULC are twelve. The regression was run separately for each class with individual drivers. Logistic regression is adopted for analysis because of dichotomous nature of LULC classes (Mac Nally, 2000; Millington et al., 2007; Martinez et al., 2011). The SPSS package is used to carry out regression analysis.
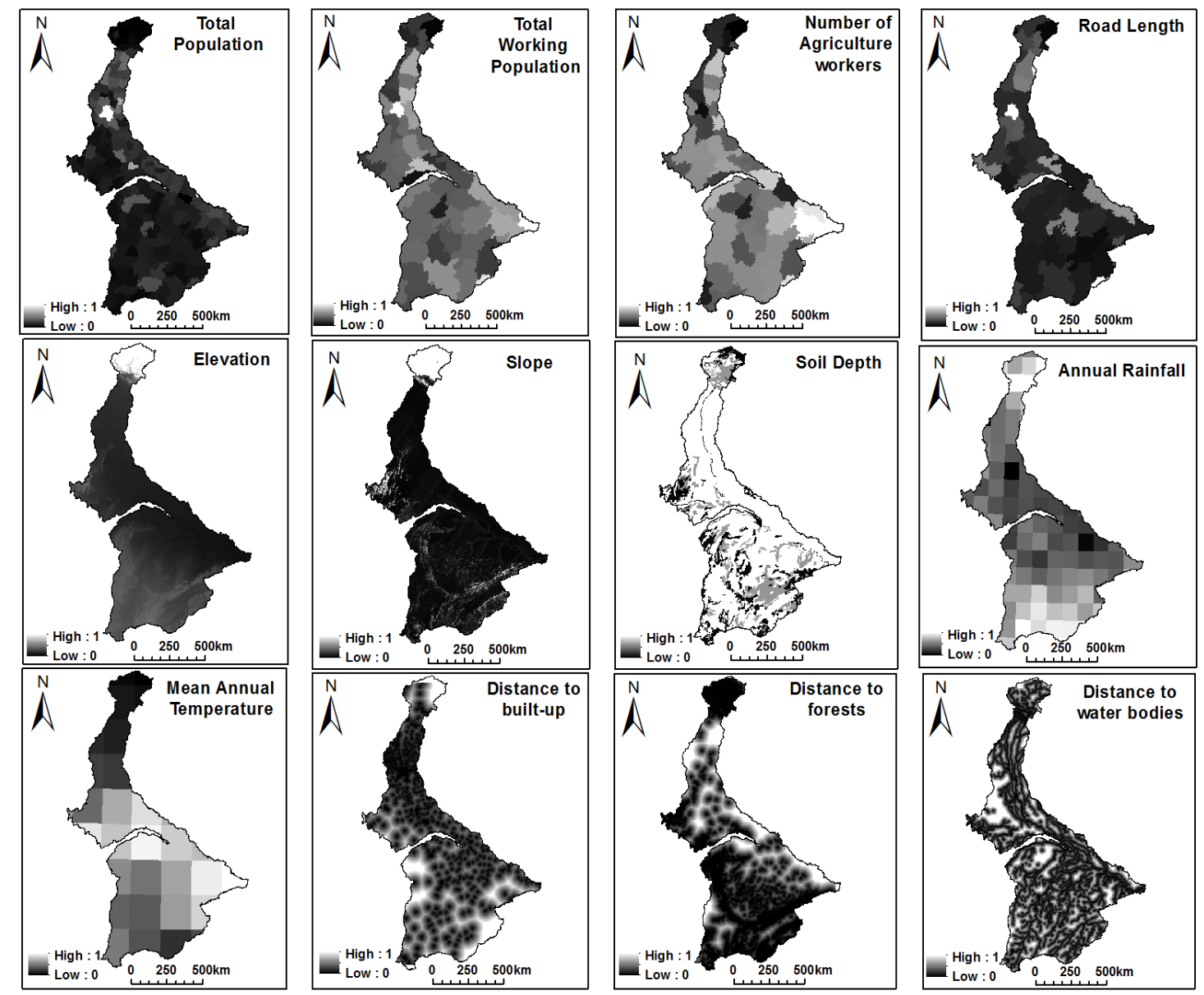

Figure 4. Normalized drivers datasets used in the study

The $\beta$ values were used to express the possible relationship between LULC classes and driving forces. Multi-collinearity between driving factors has been checked before running the regression in order to reduce the errors in parameter estimates and biasness in the outcome (MacNally, 2000). For testing multi-collinearity between independent variables, tolerance values $\left(1-\mathrm{R}^{2}\right)$ and variance inflation factors (VIF) were used. If VIF values are smaller than 10 and the tolerance values are greater than 0.1 , it indicates that there is no multi-collinearity issue between the drivers (Obrien, 2007).

The goodness of fit of the model is evaluated by relative operating characteristic (ROC) Curve. The ROC indicates whether the spatial pattern of LULC classes can be easily explained by the independent variables. The ROC value above 0.5 is good, above 
0.6 is better and value closer to 1 is categorized as perfect for the logistic regression model performance (Hosmer and Lemeshow, 2000; Pontius and Schneider, 2001).

\section{Results}

\section{Land use and land cover change analysis}

The areal extent of LULC classes in the study area is shown in Table 4. The results of LULC changes from 1985 to 1995,1995 to 2005 and 1985 to 2005 are summarized in Tables $5 a, 5 b$ and $5 c$, respectively. It is observed from Table 4 that cropland is the dominant LULC type with $66.1 \%$ area in 1985, 67.2\% area in 1995 and $67.9 \%$ area in 2005. Cropland and built-up classes show increasing trend from 1985 to 2005 . There is a continuous increase in built-up areas around major cities like Delhi during study period as a result of development in various sectors like employment opportunities, better socioeconomic conditions for living and technology. On the other hand, forest shows decreasing trend from 1985 to 2005. This decrease in forest cover is mainly attributed to fragmentation, urbanisation, cropland expansion and construction of reservoirs and dams. Grassland, barren land, permanent wetland and water bodies also show decreasing trend from 1985 to 2005 . In case of plantation class, its areal extent decreases marginally from 1985 to 1995 and increases from 1995 to 2005. An increasing trend is observed in case of shrub land and wasteland, while water bodies show decreasing trend.

The transition of one LULC class to other LULC class can be seen from Tables $5 a$, $5 b$ and $5 c$, respectively. The observation indicates that four LULC classes i.e. built-up, cropland, forest and water bodies showed major conversions. There is a gain in built-up and cropland areas. The change in built-up includes transitions from cropland, shrub land, wasteland, grassland and forest. The gain in cropland includes transitions from forests, grassland, shrub land, water bodies and wasteland. The forest and water bodies also represent important transitions. The forest transition mainly includes transition to cropland, shrub land, plantation and built-up areas. With respect to water bodies, it is converted to cropland, shrub land and wasteland. The rest of LULC classes show minor conversions. The change in areal extent of LULC classes and a few locations of LULC change from 1985 to 2005 are shown in Fig. 5 and Fig. 6.

Table 4. Areal extent of LULC classes in 1985, 1995 and 2005

\begin{tabular}{|lllllll|}
\hline LULC & \multicolumn{3}{c}{$\mathbf{k m}^{\mathbf{2}}$} & & \multicolumn{3}{c|}{ \% of Total Area } \\
Classes & $\mathbf{1 9 8 5}$ & $\mathbf{1 9 9 5}$ & $\mathbf{2 0 0 5}$ & $\mathbf{1 9 8 5}$ & $\mathbf{1 9 9 5}$ & $\mathbf{2 0 0 5}$ \\
\hline BL & 7487 & 7396 & 6463 & 3.8 & 3.7 & 3.2 \\
BU & 1754 & 2481 & 3729 & 0.9 & 1.2 & 1.9 \\
CL & 131899 & 133795 & 135119 & 66.1 & 67.2 & 67.9 \\
F & 33951 & 32090 & 30570 & 17.1 & 16.1 & 15.4 \\
GL & 846 & 663 & 522 & 0.4 & 0.3 & 0.3 \\
PL & 683 & 678 & 692 & 0.3 & 0.3 & 0.3 \\
PW & 117 & 101 & 98 & 0.1 & 0.1 & 0.0 \\
SL & 12215 & 12385 & 12414 & 6.1 & 6.2 & 6.2 \\
WB & 4623 & 4020 & 3738 & 2.3 & 2.0 & 1.9 \\
WL & 4565 & 4531 & 4795 & 2.3 & 2.3 & 2.4 \\
\hline
\end{tabular}


Table 5. Change area matrix of LULC classes: (a) from 1985 to 1995, (b) 1995 to 2005 and (c) 1985 to 2005 .

(a) 1985 to 1995

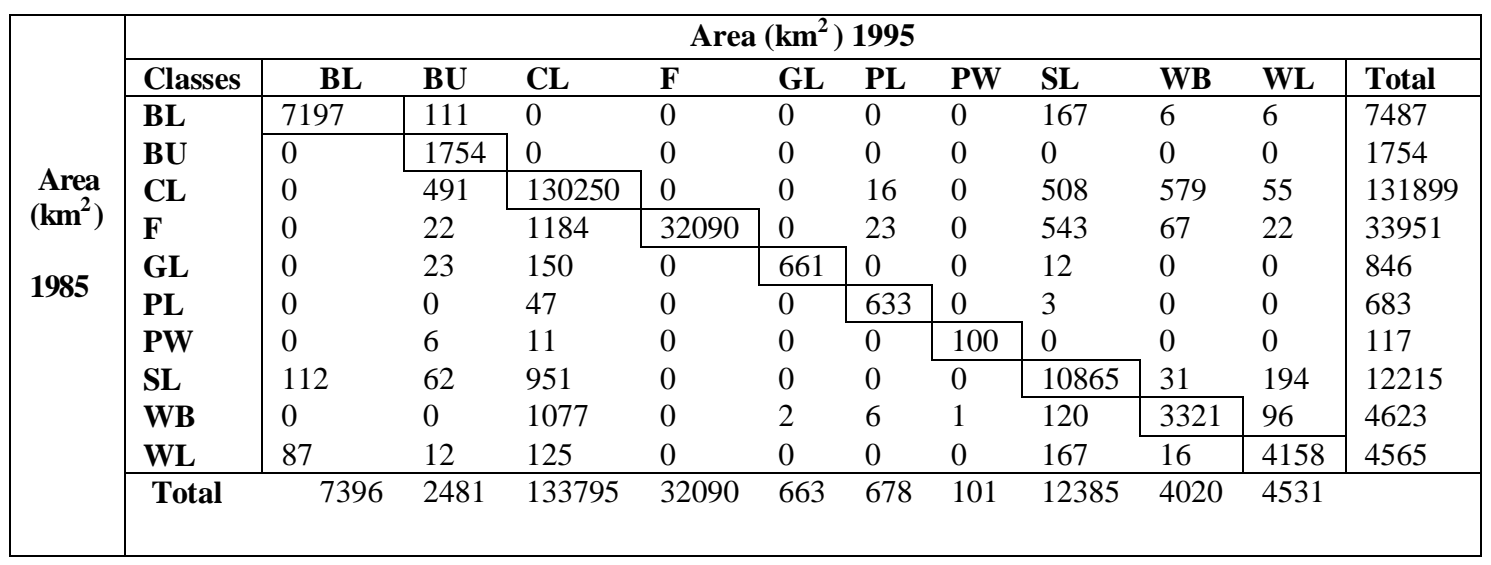

(b) 1995 to 2005

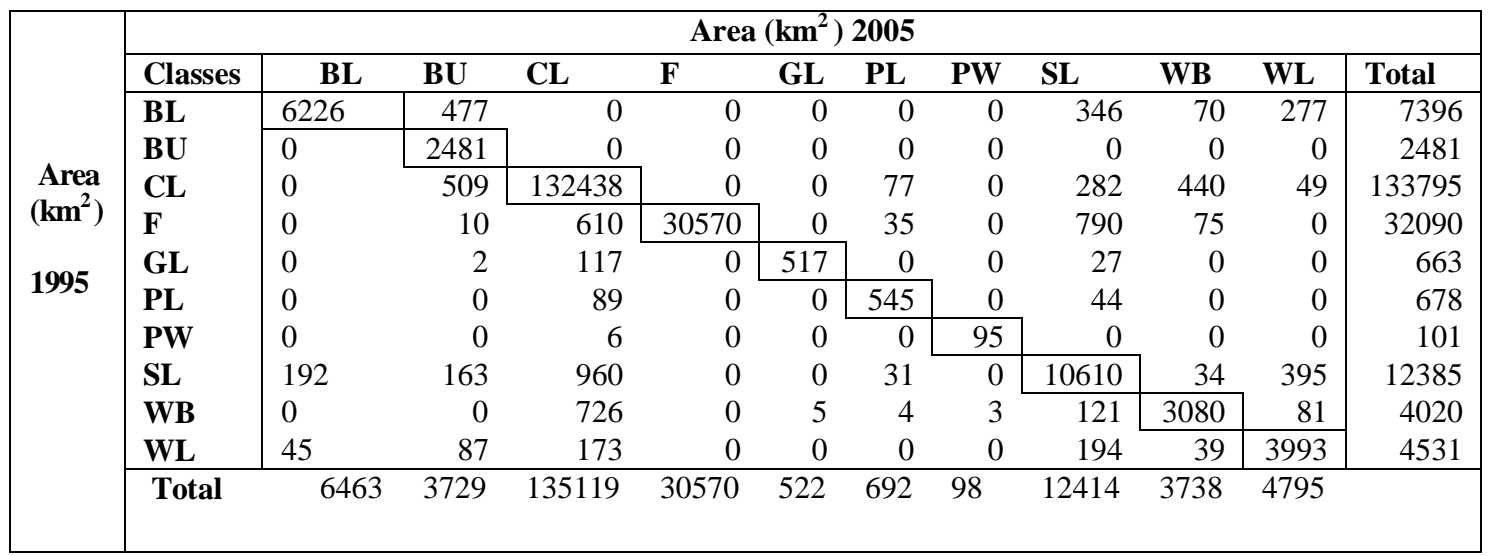

(c) 1985 to 2005

\begin{tabular}{|c|c|c|c|c|c|c|c|c|c|c|c|c|}
\hline \multirow{6}{*}{$\begin{array}{r}\text { Area } \\
\left(\mathbf{k m}^{2}\right)\end{array}$} & \multicolumn{12}{|c|}{ Area $\left(\mathrm{km}^{2}\right) 2005$} \\
\hline & Classes & BL & BU & $\mathbf{C L}$ & $\mathbf{F}$ & GL & PL & PW & SL & WB & $\mathbf{W L}$ & Total \\
\hline & $\overline{B L}$ & 6232 & 410 & 0 & 0 & 0 & 0 & 0 & 352 & 0 & 493 & 7487 \\
\hline & BU & 0 & 1754 & 0 & 0 & 0 & 0 & 0 & 0 & 0 & 0 & 1754 \\
\hline & CL & 0 & 1300 & 129746 & 0 & 0 & 21 & 0 & 157 & 593 & 82 & 131899 \\
\hline & $\mathbf{F}$ & 0 & 112 & 1719 & 30570 & 0 & 61 & 0 & 1396 & 93 & 0 & 33951 \\
\hline \multirow{7}{*}{1985} & GL & 0 & 27 & 299 & 0 & 463 & 0 & 0 & 57 & 0 & 0 & 846 \\
\hline & PL & 0 & 0 & 115 & 0 & 0 & 521 & 0 & 47 & 0 & 0 & 683 \\
\hline & PW & 0 & 0 & 15 & 0 & 0 & 0 & 98 & 0 & 0 & 4 & 117 \\
\hline & SL & 186 & 93 & 1248 & 0 & 52 & 84 & 0 & 10161 & 27 & 364 & 12215 \\
\hline & WB & 0 & 0 & 1144 & 0 & 7 & 5 & 0 & 169 & 2996 & 302 & 4623 \\
\hline & WL & 45 & 33 & 833 & 0 & 0 & 0 & 0 & 75 & 29 & 3550 & 4565 \\
\hline & Total & 6463 & 3729 & 135119 & 30570 & 522 & 692 & 98 & 12414 & 3738 & 4795 & \\
\hline
\end{tabular}

BL- Barren land, BU- Built-up, CL- Cropland, F- Forest, GL- Grassland, PL- Plantation, PW- Permanent Wetland, SL- Shrub land, WB- Water bodies, WL- Wasteland. 


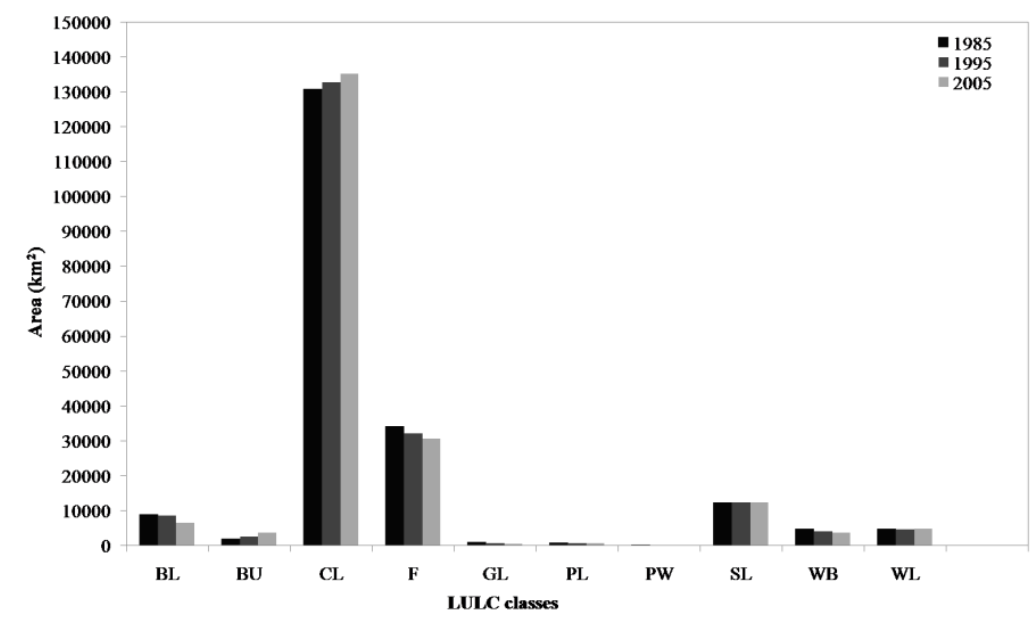

BL- Barren land, BU- Built-up, CL- Cropland, F- Forest, GL- Grassland, PL- Plantation, PW- Permanent Wetland, SL- Shrub land, WB-Water bodies, WL- Wasteland

Figure 5. Changes in the areal extent of LULC classes during 1985, 1995 and 2005
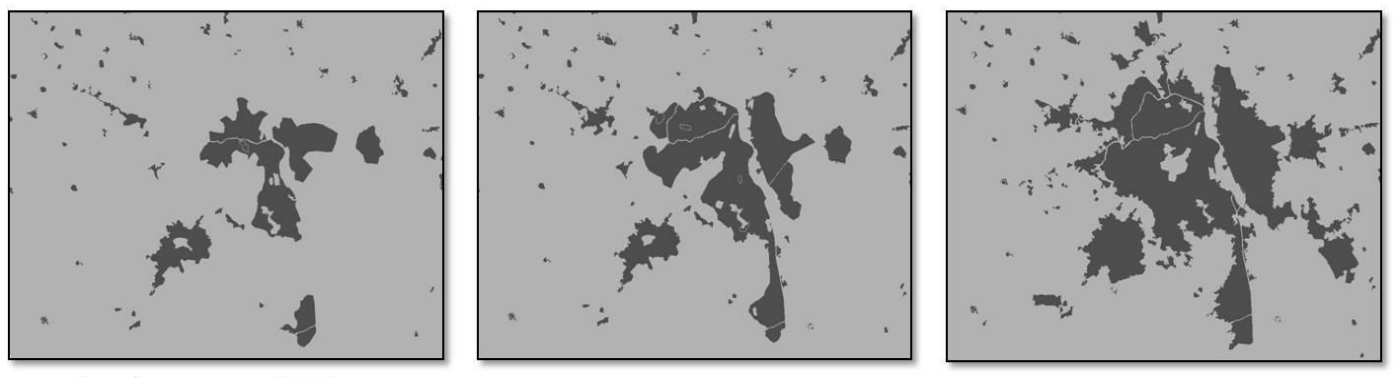

(a) Built-up Others
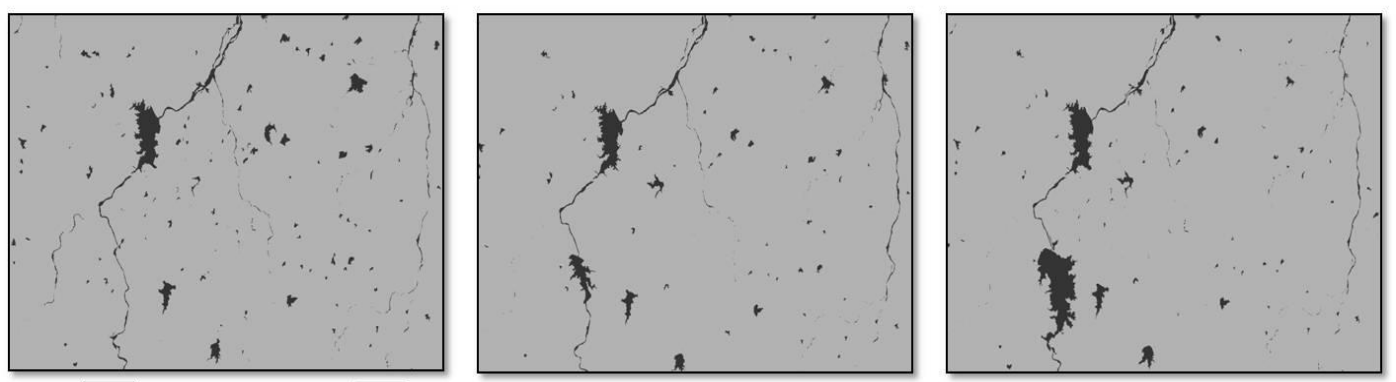

\section{(b) Water bodies Others}
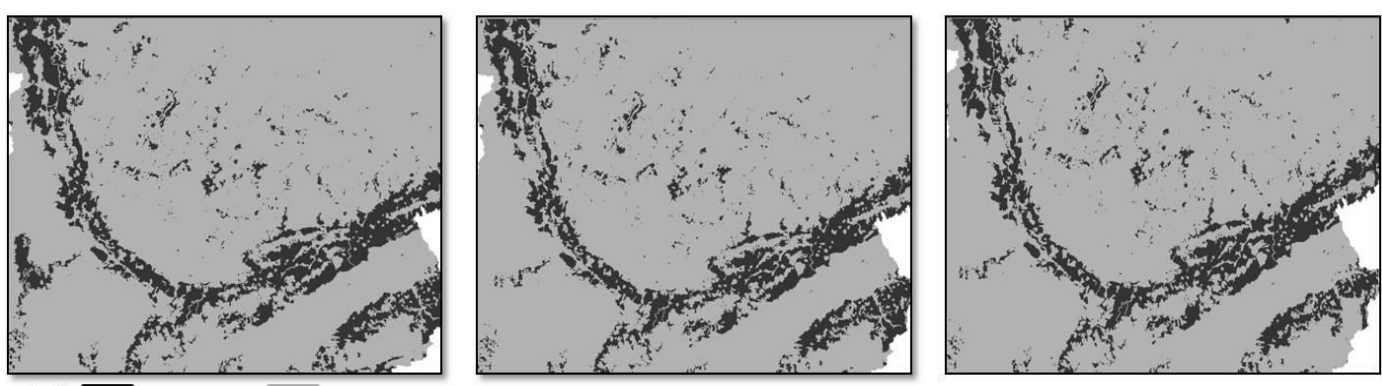

(c) Forest Others

Figure 6. A few locations of LULC changes in the study area: (a) increase in the built-up areas at the expanse of shrub land, agricultural and forest around Delhi; $(b)$ changes in part of water bodies of Madhya Pradesh; and (c) decrease in forest in part of Madhya Pradesh. 


\section{Regression analysis}

Before running logistic regression we have tested multi-collinearity between independent variables in SPSS software. No multi-collinearity issues between drivers are found as variance inflation factor (VIF) and tolerance values for all drivers are smaller than 10 and greater than 0.1 , respectively. The VIF and tolerance values to check the multi-collinearity for drivers of 1995 are shown in Table 6. The performance of logistic regression was also evaluated on the basis of ROC curve and it has been observed that ROC values for all the classes lie between 0.5 and 1 indicating that the that performance of logistic regression is good enough to explain the patterns of LULC change by the drivers. The results of logistic regression with $\beta$ and ROC values for 1995 and 2005 are summarized in Table 7.

Table 6. VIF and tolerance values to check multi-collinearity between drivers of 1995

\begin{tabular}{|c|c|c|c|c|c|c|c|c|c|c|c|c|c|}
\hline DRIVERS & & 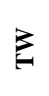 & ô & 岂 & 五 & $\stackrel{p}{a^{\prime}}$ & $\begin{array}{l}0 \\
\tilde{x} \\
a^{\prime}\end{array}$ & $\sum^{\infty}$ & 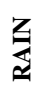 & $\sum_{i=1}^{\hat{E}}$ & $\frac{\sqrt[n]{2}}{0}$ & 鸹点 & 疍 \\
\hline \multirow[t]{2}{*}{ TW } & VIF & & 1.9 & 1.7 & 3.5 & 1.1 & 1.2 & 1.0 & 1.9 & 3.4 & 4.4 & 1.0 & 4.5 \\
\hline & tolerance & & 0.5 & 0.5 & 0.2 & 0.8 & 0.7 & 0.9 & 0.5 & 0.2 & 0.2 & 0.9 & 0.2 \\
\hline \multirow[t]{2}{*}{ POP } & VIF & 2.7 & & 1.7 & 3.5 & 1.1 & 1.2 & 1.0 & 2.0 & 3.4 & 4.4 & 1.0 & 4.5 \\
\hline & tolerance & 0.3 & & 0.5 & 0.2 & 0.8 & 0.7 & 0.9 & 0.4 & 0.2 & 0.2 & 0.9 & 0.2 \\
\hline \multirow[t]{2}{*}{$\overline{\text { AGR }}$} & VIF & 3.8 & 2.7 & & 3.5 & 1.1 & 1.2 & 1.0 & 1.9 & 3.4 & 4.4 & 1.0 & 4.5 \\
\hline & tolerance & 0.2 & 0.3 & & 0.2 & 0.8 & 0.7 & 0.9 & 0.5 & 0.2 & 0.2 & 0.9 & 0.2 \\
\hline \multirow[t]{2}{*}{ RD } & VIF & 6.0 & 4.3 & 2.8 & & 1.1 & 1.2 & 1.0 & 1.8 & 3.4 & 4.4 & 1.0 & 4.5 \\
\hline & tolerance & 0.2 & 0.2 & 0.3 & & 0.8 & 0.7 & 0.9 & 0.5 & 0.2 & 0.2 & 0.9 & 0.2 \\
\hline \multirow[t]{2}{*}{ D_BU } & VIF & 6.0 & 4.3 & 2.8 & 3.5 & & 1.2 & 1.0 & 1.9 & 3.3 & 4.4 & 1.0 & 4.5 \\
\hline & tolerance & 0.2 & 0.2 & 0.3 & 0.2 & & 0.7 & 0.9 & 0.5 & 0.2 & 0.2 & 0.9 & 0.2 \\
\hline \multirow{2}{*}{ D_FRS } & VIF & 6.0 & 4.3 & 2.8 & 3.5 & 1.1 & & 1.0 & 1.8 & 3.3 & 4.4 & 1.0 & 4.5 \\
\hline & tolerance & 0.2 & 0.2 & 0.3 & 0.2 & 0.8 & & 0.9 & 0.5 & 0.3 & 0.2 & 0.9 & 0.2 \\
\hline \multirow[t]{2}{*}{ D_WB } & VIF & 6.0 & 4.3 & 2.8 & 3.5 & 1.1 & 1.2 & & 2.0 & 3.4 & 4.4 & 1.0 & 4.5 \\
\hline & tolerance & 0.2 & 0.2 & 0.3 & 0.2 & 0.8 & 0.7 & & 0.4 & 0.2 & 0.2 & 0.9 & 0.2 \\
\hline \multirow[t]{2}{*}{ RAIN } & VIF & 6.0 & 4.3 & 2.7 & 3.3 & 1.1 & 1.1 & 1.0 & & 3.3 & 4.4 & 1.0 & 4.5 \\
\hline & tolerance & 0.2 & 0.2 & 0.3 & 0.2 & 0.8 & 0.8 & 0.9 & & 0.2 & 0.2 & 0.9 & 0.2 \\
\hline \multirow[t]{2}{*}{ TEMP } & VIF & 6.0 & 4.3 & 2.8 & 3.5 & 1.1 & 1.2 & 1.0 & 1.9 & & 3.9 & 1.0 & 4.0 \\
\hline & tolerance & 0.2 & 0.2 & 0.3 & 0.2 & 0.8 & 0.8 & 0.9 & 0.5 & & 0.2 & 0.9 & 0.2 \\
\hline \multirow[t]{2}{*}{ SLOPE } & VIF & 6.0 & 4.3 & 2.8 & 3.5 & 1.1 & 1.2 & 1.0 & 2.0 & 3.0 & & 1.0 & 3.1 \\
\hline & tolerance & 0.2 & 0.2 & 0.3 & 0.2 & 0.8 & 0.7 & 0.9 & 0.4 & 0.3 & & 0.9 & 0.3 \\
\hline SOIL & VIF & 6.0 & 4.3 & 2.8 & 3.5 & 1.1 & 1.2 & 1.0 & 2.0 & 3.4 & 4.4 & & 4.5 \\
\hline DEPTH & tolerance & 0.2 & 0.2 & 0.3 & 0.2 & 0.8 & 0.7 & 0.9 & 0.4 & 0.2 & 0.2 & & 0.2 \\
\hline \multirow[t]{2}{*}{ ELEV } & VIF & 6.0 & 4.3 & 2.7 & 3.5 & 1.1 & 1.2 & 1.0 & 1.9 & 3.0 & 3.0 & 1.0 & \\
\hline & tolerance & 0.2 & 0.2 & 0.3 & 0.2 & 0.8 & 0.8 & 0.9 & 0.5 & 0.3 & 0.3 & 0.9 & \\
\hline
\end{tabular}

VIF- Variance inflation factor, TW- Total working population, POP- Total population, AGR- Number of agriculture workers, RD- Road length, D_BU- Distance to built-up, D_FRS- Distance to forests, D_WB- Distance to water bodies, RAIN- Annual rainfall, TEMP: Mean annual temperature, ELEV- Elevation.

The logistic regression results for built-up class show that total population ( $\beta$ : 4.23 , $4.75)$, total working population $(\beta: 4.59,5.10)$ and road length $(\beta: 3.58,2.16)$ for 1995 and 2005 have strong positive influence for built-up area to change. The number of agriculture workers $(\beta:-4.11,-5.43)$ show strong negative relation with built-up class. With respect to proximity drivers, distance to forests $(\beta:-0.10,-0.57)$ have negative and distance to water bodies $(\beta: 4.01,2.58)$ have positive relation. Physical drivers, i.e. slope $(\beta$ : $-6.52,-6.16)$, elevation $(\beta:-15.82,-13.21)$, annual rainfall $(\beta:-5.15,-4.57)$ and mean annual temperature $(\beta$ : $-0.64,-0.68)$ have negative effect for the probability of finding built up areas.

The cropland class has positive relation with total population $(\beta: 0.26,0.15)$, total working population $(\beta: 2.23,0.52)$ and number of agriculture workers $(\beta: 2.28,1.45)$. 
The negative $\beta$ values for road length ( $\beta$ : $-0.14,-2.91)$, distance to built-up ( $\beta$ : -1.42 , $2.39)$ and distance to forests $(\beta$ : $-0.05,-0.61)$ show that as distance to built-up and forests increases, the probability of finding cropland class decreases. Distance to water bodies $(\beta: 5.03,2.09)$ is positively related to cropland class that increases the probability of finding cropland areas near the water bodies. With regard to physical drivers, slope $(\beta:-17.29,-10.98)$, elevation $(\beta:-16.91,-12.17)$ and mean annual temperature $(\beta:-2.62$, -2.60) have negative influence on the probability of finding cropland class; whereas, annual rainfall $(\beta: 9.04,8.13)$ and soil depth $(\beta: 0.22,0.21)$ show positive influence for the probability of finding cropland class.

Table 7. Result of logistic regression between LULC classes and drivers of 1995 and 2005

\begin{tabular}{|c|c|c|c|c|c|c|c|c|c|c|c|c|c|}
\hline 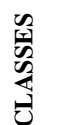 & 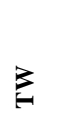 & ธิ & 원 & $\widehat{\approx}$ & $\begin{array}{l}D^{\prime} \\
a^{\prime}\end{array}$ & $\begin{array}{l}\frac{n}{0} \\
\frac{0}{\mid} \\
\theta^{\prime}\end{array}$ & $\frac{n}{\theta^{\prime}}$ & $\underset{\Xi}{Z}$ & 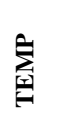 & 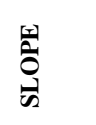 & 亏) & 空 & 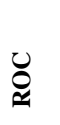 \\
\hline & \multicolumn{12}{|c|}{$\beta$ values for 1995} & \\
\hline BU & 4.59 & 4.23 & -4.11 & 3.58 & -8.11 & -0.10 & 4.01 & -5.15 & -0.64 & -6.52 & 0.16 & -15.82 & 0.82 \\
\hline CL & 2.23 & 0.26 & 2.28 & -0.14 & -1.42 & -0.05 & 5.03 & 9.04 & -2.62 & -17.29 & 0.22 & -16.91 & 0.80 \\
\hline $\mathbf{F}$ & -7.80 & -9.19 & -2.77 & -3.85 & -1.50 & -8.29 & 0.50 & 4.12 & -8.31 & 6.40 & -0.31 & 6.89 & 0.84 \\
\hline SL & -0.88 & -0.63 & -0.60 & -0.29 & 1.09 & -3.73 & 0.20 & 0.67 & 0.43 & 1.32 & -0.03 & 0.99 & 0.62 \\
\hline BL & 1.95 & -4.67 & -3.94 & -1.16 & -8.96 & 3.32 & -0.29 & -5.86 & 2.65 & 2.13 & -0.16 & 1.22 & 0.84 \\
\hline WL & -0.06 & -4.28 & 1.96 & 1.60 & -0.47 & 2.72 & -1.85 & -3.39 & 53.56 & -4.06 & 0.13 & -90.93 & 0.87 \\
\hline WB & -0.14 & -1.11 & -1.64 & -0.27 & 0.88 & 0.33 & -0.47 & -0.11 & 0.34 & -1.56 & 0.02 & -7.26 & 0.63 \\
\hline 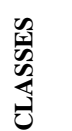 & 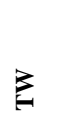 & ธิ & 嵌 & $\widehat{\approx}$ & $\overbrace{}^{n}$ & $\frac{\mathscr{n}}{\sigma_{1}^{\prime}}$ & $\sum^{\infty}$ & $\frac{\mathbf{Z}}{\simeq}$ & 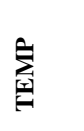 & 罢 & ప్ర & 空 & $\begin{array}{l}\text { Ð } \\
\approx\end{array}$ \\
\hline \multicolumn{14}{|c|}{$\beta$ values for 2005} \\
\hline BU & 5.10 & 4.75 & -5.43 & 2.16 & -8.94 & -0.57 & 2.58 & -4.57 & -0.68 & -6.16 & 0.19 & -13.21 & 0.82 \\
\hline CL & 0.52 & 0.15 & 1.45 & -2.91 & -2.39 & -0.61 & 2.09 & 8.13 & -2.60 & -10.98 & 0.21 & -12.17 & 0.79 \\
\hline $\mathbf{F}$ & -4.10 & -7.55 & -1.41 & -35.19 & -1.67 & -4.13 & 2.36 & 3.95 & -8.18 & 6.16 & -0.86 & 6.58 & 0.84 \\
\hline SL & -1.25 & -0.34 & -0.71 & -4.67 & 1.12 & -1.40 & 0.44 & 1.32 & 0.79 & 1.16 & -0.06 & 0.98 & 0.62 \\
\hline BL & 0.98 & -15.67 & -3.56 & -0.30 & -1.47 & 3.20 & -2.36 & -6.22 & 21.98 & 0.87 & -0.08 & 1.51 & 0.89 \\
\hline WL & -0.09 & -1.34 & 0.99 & 0.80 & -1.88 & 0.69 & -0.38 & -3.36 & 51.54 & -4.03 & 0.15 & -88.30 & 0.85 \\
\hline WB & -0.22 & -2.58 & -0.73 & -0.14 & 0.15 & 0.50 & -0.75 & -0.23 & 1.78 & -1.94 & 0.01 & -7.06 & 0.59 \\
\hline
\end{tabular}

Significant at 0.05 (95\% confidence level)

$\beta$ is coefficient of independent variable; ROC (Area under Curve) is a measure of how well the independent variables are correctly predicts the value of dependent variable

Dependent Variables: BL- Barren land, BU- Built-up, CL- Cropland, F- Forest, SL- Shrub land, WB- Water bodies, WL- Wasteland. Independent Variables: TW- Total working population, POP- Total population, AGR- number of agriculture workers, RD- Road length, D_BU- Distance to builtup, D_FRS- Distance to forests, D_WB- Distance to water bodies, RAIN- Annual rainfall, TEMP: Mean annual temperature, ELEV- Elevation.

With regard to forest class, total population $(\beta:-9.19,-7.55)$, total working population $(\beta:-7.80,-4.10)$, number of agriculture workers $(\beta:-2.77,-1.41)$ and road length $(\beta$ : $-3.85,-35.19)$ have negative effect for the presence of forest class. The physical drivers like annual rainfall $(\beta: 4.12,3.95)$, slope $(\beta: 6.40,6.16)$ and elevation $(\beta: 6.89,6.58)$ strongly influence presence of forest class in a positive way whereas temperature with high $\beta$ values ( $\beta$ : -8.31, -8.18) show negative effect for the presence of forest class. Distance to water bodies $(\beta: 0.50,2.36)$ has positive influence while distance to built-up $(\beta:-1.50,-1.67)$ has negative influence for the presence of forest class. The total population, total working population and road length with high negative 
$\beta$ values and physical drivers (elevation, slope and annual rainfall) with high positive $\beta$ values influence the probability of presence of forests.

In case of water bodies, total population $(\beta:-1.11,-2.58)$, total working population $(\beta:-0.14,-0.22)$, number of agriculture workers $(\beta:-1.64,-0.73)$ and road length $(\beta$ : $0.27,-0.14$ ) have negative correlation which shows that as values of these drivers increases, there is a possibility of decrease in water bodies areas. Distance to built-up ( $\beta: 0.88,0.15)$ and distance to forests $(\beta: 0.33,0.50)$ have positive effect for the presence of water bodies. Physical drivers like annual rainfall ( $\beta$ : $-0.11,-0.23)$, slope $(\beta$ : $-1.56,-1.94)$ and elevation $(\beta:-7.26,-7.06)$ have negative and mean annual temperature $(\beta: 0.34,1.78)$ has positive relation with water bodies. The total population and number of agriculture workers with negative $\beta$ values indicate pressure on the water bodies.

In case of shrub land class, total population $(\beta$ : $-0.63,-0.34)$, total working population $(\beta$ : $-0.88,-1.25)$, number of agriculture workers $(\beta$ : $-0.60,-0.71)$ and road length $(\beta$ : $-0.29,-4.67)$ have negative effect for the presence of shrub land class. Proximity drivers like distance to built-up $(\beta: 1.09,1.12)$ and distance to water bodies ( $\beta: 0.20,0.44)$ have positive relation while distance to forests $(\beta:-3.73,-1.40)$ has negative relation with shrub land class. Physical drivers like annual rainfall ( $\beta$ : 0.67 , $1.32)$, mean annual temperature $(\beta: 0.43,0.79)$, slope $(\beta: 1.32,1.16)$ and elevation $(\beta$ : $0.99,0.98)$ show positive relation while soil depth $(\beta$ : $-0.03,-0.06)$ show negative relation for the presence of shrub land.

In case of barren land, socioeconomic drivers like total population ( $\beta$ : $-4.67,-15.67)$, number of agriculture workers $(\beta:-3.94,-3.56)$ and road length $(\beta:-1.16,-0.30)$ show negative relation while total working population $(\beta: 1.95,0.98)$ show positive relation. The increase in distance to built-up $(\beta:-8.96,-1.47)$ and distance to water bodies $(\beta$ : $0.29,-2.36)$ decreases the probability of finding barren land decreases. Distance to forests show positive $(\beta: 3.32,3.20)$ relation with barren land. Physical drivers like annual rainfall $(\beta:-5.86,-6.22)$ and soil depth $(\beta:-0.16,-0.08)$ have negative relation while mean annual temperature $(\beta: 2.65,21.98)$, slope $(\beta: 2.13,0.87)$ and elevation $(\beta$ : $1.22,1.51)$ have positive relation for the presence of barren land.

In case of wasteland class, total population $(\beta:-4.28,-1.34)$ and total working population ( $\beta$ : $-0.06,-0.09)$ have negative influence while number of agriculture workers $(\beta: 1.96,0.99)$ and road length $(\beta: 1.60,0.80)$ have positive influence. Distance to water bodies $(\beta:-1.85$, 0.38 ) and distance to built-up ( $\beta$ : $-0.47,-1.88)$ show negative effect whereas distance to forests $(\beta: 2.72,0.69)$ shows positive effect for the presence of wasteland class. Very strong positive relation $(\beta: 53.56,51.54)$ with temperature and negative relation $(\beta:-90.93,-88.30)$ with elevation are observed for the wasteland class. Thus, physical and proximity drivers strongly influence barren land and wasteland classes.

In summary, the above results indicate that LULC in the Yamuna river basin is influenced by a multitude of drivers (socioeconomic, demographic, physical and proximity drivers) in different combinations. Since physical drivers generally have very low temporal variability, socioeconomic, demographic and proximity drivers mainly control the LULC change processes in the study area in decreasing order of importance.

\section{Discussion}

The results indicate that significant LULC changes have occurred in the basin during the study period. The major LULC changes include the continuous expansion of builtup and cropland areas and shrinkage of forest areas. The LULC transitions in the study 
are of both reversible and irreversible nature. For example, transitions like barren land to shrub land, cropland to shrub land, cropland to water bodies, cropland to plantation, forest to plantation, grassland to cropland, plantation to cropland, shrub land to barren land, water bodies to cropland are some of reversible transitions; whereas, forest to built-up, cropland to built-up, grassland to built-up and shrub land to built-up can be considered as irreversible transitions.

It is likely that these changes will affect the biodiversity, soil erosion and soil and water quality of the area; however, the magnitude of impact will depend mainly upon the direction of land conversion. Conversion of forest to cropland can result in soil erosion, if good farming techniques are not adopted (Wasige et al., 2013). Decrease in forest may lead to loss of indigenous plant species and reduction of biodiversity (Aduah, 2014). It can be observed from change matrices that decrease in forest class are mainly due to conversion to cropland and built-up as a result of anthropogenic pressure. Forests with fertile soil, particularly in Indo-Gangetic plains, are generally more prone to deforestation for agriculture expansion (Geist and Lambin, 2004). While expansion of agricultural activity, as observed during the study period, is expected to have impact on freshwater ecosystem (Tilman, 1999), urban expansion and agriculture activities affect the water quality of the streams and reservoirs via increase in concentration of nutrients (Bonansea et al., 2016). Habitat loss and degradation are the major causes of biodiversity loss (Convention on biological diversity, 2010). The demand for additional land increases with increase in population that further causes the conversion of forests and cropland to built-up. Land cover changes like increase in built-up can reduce infiltration by virtue of impervious nature leading to increased soil erosion, sedimentation and pollution of river waters (Rogers, 1994).

The LULC changes in the basin are attributed to mainly socioeconomic, demographic and proximity drivers. The high $\beta$ values of total population, number of agriculture workers, total working population and road length obtained from statistical analysis indicate the importance of these drivers on LULC changes. Among physical and proximity drivers, annual rainfall, slope, elevation and distance to water bodies are the main drivers contributing to LULC changes in the study area. The high negative $\beta$ values for elevation and slope have a negative effect for the presence of water bodies in areas with high slope and elevation while the presence of forest is positively related with an increase in elevation and rising slope (Oprsal et al., 2016). Further, total population and number of agriculture workers with negative $\beta$ values indicate pressure of population increase and agricultural expansion on water bodies. With agricultural expansion and increase in population, it is obvious that the demand for water supply has also increased in the basin over time. To meet this increased water demand, the Yamuna water is abstracted at different locations like Dakpathar, Hathinikund/ Tajewala, Wazirabad, Okhla and Gokul barrage for drinking water supply, irrigation, hydropower generation, etc. Various dams and reservoirs (e.g. Renuka, Lakhawar, Vyasi on Yamuna, Keshua on Tons, Rajghat on Betwa) have been constructed on river Yamuna and its tributaries. Such man-made interventions along the river courses may have an adverse impact on the overall quality of river water and aquatic ecosystem (Mishra, 2010).

On one hand, the basin has undergone phenomenal development with great advancement in different sectors like employment, health, education, transport, agriculture and technology, its population has also increased manifold simultaneously. So, there is a need to adopt sustainable development strategy to bring harmony between development, environment and society. The findings of the present study provide an 
understanding of LULC change processes which can be used as an input for sustainable land management not only in Yamuna river basin but also in other similar river basins.

One of the major limitations of the present study is that the drivers, particularly socioeconomic, demographic and meteorological (rainfall and temperature), were available at different scales (resolutions). It required a considerable effort in collating and converting the socioeconomic and demographic data available in tabular form to geo-referenced spatial format before carrying out statistical analysis to explore dependencies of drivers on LULC change. Despite limitations, the present study based on remote sensing, GIS and statistical analysis clearly brings out the linkage between LULC change and the drivers of such change at river basin scale. The statistical analysis at different scales (i.e. grid size) may further improve understanding the causes of LULC change. The results of this study provide first and foremost input towards simulating future LULC scenario.

\section{Conclusions}

In this study, we have investigated LULC change and driving forces causing such change in the Yamuna river basin of India. The major LULC changes observed during 1985-2005 at decadal interval are increase in cropland and built-up and decrease in forest and water bodies. The dominant processes of the LULC changes include transitions from forest, grassland, shrub land, water bodies and wasteland to cropland; transitions from cropland, shrub land, wasteland, grassland and forest to built-up; and conversion of forest to cropland, shrub land, plantation and built-up. The decrease in forest cover is mainly attributed to fragmentation, urbanisation, cropland expansion and construction of reservoirs and dams. Further, it is noticed that most of LULC transitions in the study are reversible in nature.

The statistical analysis suggests that LULC changes are driven by a combination of socioeconomic, demographic, physical and proximity drivers. However, in general it is found that the socioeconomic, demographic and proximity drivers mainly influence the LULC change processes in decreasing order of importance. The population increase with accompanied development exerted pressure on existing land in pursuit of better living standards leading to LULC change.

The present study is an example to understand the dynamics and causes of LULC change using multiple techniques, i.e. remote sensing, GIS and statistics. Despite limitations of having driver datasets at coarse and different scales, the study clearly brings out the linkage between LULC change and the drivers of such change in a large study area of river basin size. The statistical analysis at different scales (i.e. grid size) may further improve understanding the causes of LULC change. The insights gained through this study will be useful in simulating future LULC scenarios and thus in providing inputs to sustainable land management policy making.

Acknowledgements. We thank ISRO-Geosphere Biosphere Programme (GBP) for making us available decadal satellite images and reference LULC maps. We are thankful to ISRO-GBP LULC project team for fruitful discussions. We also acknowledge Census of India, India Meteorological Department and University of Maryland for socioeconomic, climatic data and satellite data, respectively. We are grateful to Director, Indian Institute of Remote Sensing, Dehradun for encouragement and support to carry out this study. We thank the anonymous reviewers for their helpful comments and suggestions to improve the quality of this manuscript. 


\section{REFERENCES}

[1] Aduah, M.S., Warburton, M.L., Jewitt, G. (2015): Analysis of land cover changes in the Bonsa catchment, Ankobra basin, Ghana.-Applied ecology and environmental research 13(4): 935-955.

[2] Bonansea, M., Ledesma, C., Rodriguez, M.C. (2016): Assessing the impact of land use and land cover on water quality in the watershed of a reservoir. -Applied ecology and environmental research 14(2): 447-456.

[3] Congalton, R.G. (1991): A review of assessing the accuracy of classifications of remotely sensed data. -Remote sensing of environment 37(1): 35-46.

[4] Hosmer, D.W., Lemeshow, S. (2000): Applied Logistic Regression. -John Wiley and Sons, New Jersey, USA.

[5] Lambin, E.F., Turner, B.L., Geist, H.J., Agbola, S.B., Angelsen, A., Bruce, J.W., Coomes, O.T., Dirzo, R., Fischer, G., Folke, C., George, P.S. (2001): The causes of landuse and land-cover change: moving beyond the myths.-Global environmental change 11(4): 261-269.

[6] Loveland, T.R., Belward, A.S. (1997): The IGBP-DIS global $1 \mathrm{~km}$ land cover data set, DISCover: first results. -International Journal of Remote Sensing 18(15): 3289-3295.

[7] Mac Nally, R. (2000): Regression and model-building in conservation biology, biogeography and ecology: the distinction between-and reconciliation of-'predictive'and 'explanatory' models. -Biodiversity \& Conservation 9(5): 655-671.

[8] Martinez, J.M.A., Suarez-Seoane, S., Calabuig, E.D.L. (2011): Modelling the risk of land cover change from environmental and socio-economic drivers in heterogeneous and changing landscapes: The role of uncertainty. -Landscape and Urban Planning 101(2): 108-119.

[9] Millington, J.D., Perry, G.L., Romero-Calcerrada, R. (2007): Regression techniques for examining land use/cover change: a case study of a Mediterranean landscape. Ecosystems 10(4): 562-578.

[10] Mishra, A.K. (2010): A River about to Die: Yamuna. -J. Water Resource and Protection 2: 489-500.

[11] Nefeslioglu, H.A., Gokceoglu, C., Sonmez, H. (2008): An assessment on the use of logistic regression and artificial neural networks with different sampling strategies for the preparation of landslide susceptibility maps. -Engineering Geology 97(3): 171-191.

[12] Obrien, R.M. (2007): A caution regarding rules of thumb for variance inflation factors. Quality \& Quantity 41(5): 673-690.

[13] Oprsal, Z., Kladivo, P., Machar, I. (2016): The role of selected biophysical factors in long-term land-use change of cultural landscape. -Applied ecology and environmental research 14(2): 23-40.

[14] Outlook, G.B. 3 (2010): Secretariat of the convention on biological diversity. Montreal 94.

[15] Pontius, R.G., Schneider, L.C. (2001): Land-cover change model validation by an ROC method for the Ipswich watershed, Massachusetts, USA.-Agriculture, Ecosystems \& Environment 85(1): 239-248.

[16] Rai, R.K., Upadhyay, A., Ojha, C.S.P., Singh, V.P. (2012): Salient Features of the Yamuna River Basin. -Springer, Netherlands.

[17] Rogers, P. (1994): Hydrology and Water Quality. - In: Meyer, W.B., Turner Ii, B.L. (eds.) Changes in Land Use and Land Cover: A Global Perspective, Cambridge University Press, Cambridge, UK.

[18] Roy, P.S., Roy, A., Joshi, P.K., Kale, M.P., Srivastava, V.K., Srivastava, S.K., Dwevidi, R.S., Joshi, C., Behera, M.D., Meiyappan, P., Sharma, Y. (2015): Development of decadal (1985-1995-2005) land use and land cover database for India.-Remote Sensing 7(3): 2401. 
[19] Shen, Z., Lu, C., Yin, R., Qi, J. (2013): Land cover changes in Northeast China from the late 1970s to 2004. -Applied ecology and environmental research 11(1): 67-78.

[20] Tian, H., Banger, K., Bo, T., Dadhwal, V.K. (2014): History of land use in India during 1880-2010: Large-scale land transformations reconstructed from satellite data and historical archives. -Global and Planetary Change 121: 78-88.

[21] Tilman, D. (1999): Global environmental impacts of agricultural expansion: the need for sustainable and efficient practices. -Proceedings of the National Academy of Sciences 96(11): 5995-6000.

[22] Tripathi, A., Prasad, A.R. (2010): Agricultural development in India since independence: A study on progress, performance, and determinants. -Journal of emerging knowledge on emerging markets $1(1): 8$.

[23] United Nations Centre for Human Settlements (1996): An urbanizing world: global report on human settlements. -Oxford University Press, USA.

[24] Veldkamp, A., Fresco, L.O. (1997): Reconstructing land use drivers and their spatial scale dependence for Costa Rica (1973 and 1984). -Agricultural systems 55(1): 19-43.

[25] Verburg, P.H., Van Eck, J.R.R., De Nijs, T.C., Dijst, M.J., Schot, P. (2004): Determinants of land-use change patterns in the Netherlands. -Environment and Planning B: Planning and Design 31(1): 125-150.

[26] Viles, H., Goudie, A. (1997): The Earth Transformed: An Introduction to the Human Impact on the Environment. -Blackwell, Oxford, UK.

[27] Vu, Q.M., Le, Q.B., Frossard, E., Vlek, P.L. (2014): Socio-economic and biophysical determinants of land degradation in Vietnam: An integrated causal analysis at the national level. -Land Use Policy 36: 605-617.

[28] Wang, D., Gong, J., Chen, L., Zhang, L., Song, Y., Yue, Y. (2013): Comparative analysis of land use/cover change trajectories and their driving forces in two small watersheds in the western Loess Plateau of China. -International Journal of Applied Earth Observation and Geoinformation 21: 241-252.

[29] Wasige, J.E., Groen, T.A., Smaling, E., Jetten, V. (2013): Monitoring basin-scale land cover changes in Kagera Basin of Lake Victoria using ancillary data and remote sensing. -International Journal of Applied Earth Observation and Geoinformation 21: 3242.

[30] Yirsaw, E., Wu, W., Temesgen, H., Bekele, B. (2016): Effect of temporal land use/land cover changes on Ecosystem Services Value in coastal area of China: the case of Su-XiChang region. -Applied ecology and environmental research 14(3): 409-422.

[31] Zgola, T. (2014): The response of aquatic plants to catchment land use for different types of lowland rivers. -Applied ecology and environmental research 12(1): 143-162. 


\section{APPENDICES}

Appendix 1. VIF and tolerance values to check multi-collinearity between drivers of 2005

\begin{tabular}{|c|c|c|c|c|c|c|c|c|c|c|c|c|c|}
\hline DRIVERS & & 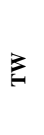 & оे & 원 & ๙ิ & $\stackrel{D}{A}^{\infty}$ & 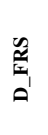 & $\frac{\infty}{a^{\prime}}$ & $\underset{\cong}{\mathbf{Z}}$ & 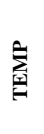 & 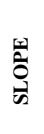 & 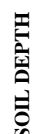 & 空 \\
\hline \multirow[t]{2}{*}{ TW } & \multirow{10}{*}{$\begin{array}{l}\text { VIF } \\
\text { tolerance } \\
\text { VIF } \\
\text { tolerance } \\
\text { VIF } \\
\text { tolerance } \\
\text { VIF } \\
\text { tolerance } \\
\text { VIF } \\
\text { tolerance }\end{array}$} & & 2.2 & 3.9 & 1.2 & 1.4 & 1.3 & 1.1 & 1.9 & 3.7 & 4.3 & 1.0 & 5.4 \\
\hline & & & 0.4 & 0.3 & 0.9 & 0.7 & 0.8 & 0.9 & 0.5 & 0.3 & 0.2 & 1.0 & 0.2 \\
\hline \multirow[t]{2}{*}{ POP } & & 3.4 & & 2.4 & 1.2 & 1.4 & 1.3 & 1.1 & 1.8 & 3.7 & 4.3 & 1.0 & 5.4 \\
\hline & & 0.3 & & 0.4 & 0.8 & 0.7 & 0.7 & 0.9 & 0.5 & 0.3 & 0.2 & 1.0 & 0.2 \\
\hline \multirow[t]{2}{*}{ AGR } & & 8.9 & 5.7 & & 1.2 & 1.4 & 1.3 & 1.1 & 1.8 & 3.7 & 4.3 & 1.0 & 5.4 \\
\hline & & 0.2 & 0.2 & & 0.8 & 0.7 & 0.8 & 0.9 & 0.5 & 0.3 & 0.2 & 1.0 & 0.2 \\
\hline \multirow[t]{2}{*}{ RD } & & 9.1 & 6.0 & 5.6 & & 1.4 & 1.3 & 1.1 & 1.9 & 3.7 & 4.3 & 1.0 & 5.4 \\
\hline & & 0.2 & 0.2 & 0.2 & & 0.7 & 0.8 & 0.9 & 0.5 & 0.3 & 0.2 & 1.0 & 0.2 \\
\hline \multirow[t]{2}{*}{ D_BU } & & 9.2 & 6.0 & 5.7 & 1.2 & & 1.3 & 1.0 & 1.8 & 3.6 & 4.3 & 1.0 & 5.1 \\
\hline & & 0.2 & 0.2 & 0.2 & 0.8 & & 0.8 & 1.0 & 0.6 & 0.3 & 0.2 & 1.0 & 0.2 \\
\hline \multirow[t]{2}{*}{ D_FRS } & & 9.2 & 6.0 & 5.6 & 1.2 & 1.4 & & 1.1 & 1.8 & 3.6 & 4.2 & 1.0 & 5.4 \\
\hline & tolerance & 0.2 & 0.2 & 0.2 & 0.8 & 0.7 & & 0.9 & 0.5 & 0.3 & 0.2 & 1.0 & 0.2 \\
\hline \multirow[t]{2}{*}{ D_WB } & & 9.1 & 6.0 & 5.6 & 1.2 & 1.4 & 1.3 & & 1.8 & 3.7 & 4.3 & 1.0 & 5.4 \\
\hline & tolerance & 0.2 & 0.2 & 0.2 & 0.8 & 0.7 & 0.7 & & 0.5 & 0.3 & 0.2 & 1.0 & 0.2 \\
\hline \multirow[t]{2}{*}{ RAIN } & & 9.2 & 5.9 & 5.2 & 1.2 & 1.3 & 1.3 & 1.1 & & 3.4 & 4.3 & 1.0 & 5.0 \\
\hline & tolerance & 0.2 & 0.2 & 0.2 & 0.8 & 0.8 & 0.8 & 1.0 & & 0.3 & 0.2 & 1.0 & 0.2 \\
\hline \multirow[t]{2}{*}{ TEMP } & & 9.1 & 6.0 & 5.6 & 1.2 & 1.4 & 1.3 & 1.1 & 1.7 & & 3.7 & 1.0 & 4.4 \\
\hline & tolerance & 0.2 & 0.2 & 0.2 & 0.8 & 0.7 & 0.8 & 0.9 & 0.6 & & 0.3 & 1.0 & 0.2 \\
\hline \multirow[t]{2}{*}{ SLOPE } & VIF & 9.2 & 6.0 & 5.6 & 1.2 & 1.4 & 1.3 & 1.1 & 1.9 & 3.3 & & 1.0 & 4.0 \\
\hline & tolerance & 0.2 & 0.2 & 0.2 & 0.8 & 0.7 & 0.8 & 0.9 & 0.5 & 0.3 & & 1.0 & 0.2 \\
\hline \multirow{2}{*}{ SOIL DEPTH } & & 9.2 & 6.0 & 5.7 & 1.2 & 1.4 & 1.3 & 1.1 & 1.9 & 3.7 & 4.3 & & 5.4 \\
\hline & tolerance & 0.2 & 0.2 & 0.2 & 0.8 & 0.7 & 0.7 & 0.9 & 0.5 & 0.3 & 0.2 & & 0.2 \\
\hline \multirow[t]{2}{*}{ ELEV } & VIF & 9.2 & 6.0 & 5.5 & 1.2 & 1.3 & 1.3 & 1.1 & 1.7 & 3.1 & 3.2 & 1.0 & \\
\hline & tolerance & 0.2 & 0.2 & 0.2 & 0.8 & 0.7 & 0.7 & 0.9 & 0.6 & 0.3 & 0.3 & 1.0 & \\
\hline
\end{tabular}

VIF- Variance inflation factor, TW- Total working population, POP- Total population, AGR- Number of agriculture workers, RD- Road length, D_BU- Distance to built-up, D_FRS- Distance to forests, D_WB- Distance to water bodies, RAIN- Annual rainfall, TEMP: Mean annual temperature, ELEV- Elevation

Appendix 2. Mathematical expressions, formulae used for accuracy assessment

Generate an error matrix, which sometimes is also known as confusion matrix or contingency table. In this matrix, classified data are given as rows and reference data are given as columns for each sample point. An example is illustrated below:

\begin{tabular}{|c|c|c|c|c|c|c|c|c|c|c|c|c|}
\hline \multirow{13}{*}{ 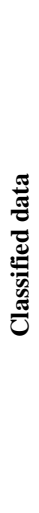 } & \multicolumn{12}{|c|}{ Reference data } \\
\hline & $\begin{array}{l}\text { LULC } \\
\text { Classes }\end{array}$ & BL & BU & CL & $\mathbf{F}$ & GL & PL & PW & SL & WB & WL & $\begin{array}{l}\text { Row } \\
\text { Total }\end{array}$ \\
\hline & BL & 519 & 1 & 23 & 87 & & & & 3 & & & 633 \\
\hline & BU & 13 & 1634 & 72 & 2 & & & 1 & 7 & 2 & & 1731 \\
\hline & CL & & 4 & 1147 & 24 & & 1 & & 25 & 5 & 3 & 1209 \\
\hline & $\mathbf{F}$ & & 5 & 109 & 1544 & & 4 & & 18 & & 1 & 1681 \\
\hline & GL & & 96 & 17 & 2 & 315 & 6 & & & 1 & & 437 \\
\hline & PL & & 3 & 12 & & 2 & 415 & & & & & 432 \\
\hline & PW & & & 8 & & & & 116 & & & & 124 \\
\hline & SL & 12 & 2 & 75 & & 46 & & & 946 & & 4 & 1085 \\
\hline & WB & & & 116 & 6 & 10 & & & 3 & 764 & & 899 \\
\hline & WL & 3 & 2 & 52 & 7 & 19 & & & 1 & 1 & 687 & 772 \\
\hline & $\begin{array}{l}\text { Column } \\
\text { Total }\end{array}$ & 547 & 1747 & 1631 & 1672 & 392 & 426 & 117 & 1003 & 773 & 695 & 9003 \\
\hline
\end{tabular}

BL- Barren land, BU- Built-up, CL- Cropland, F- Forest, GL- Grassland, PL- Plantation, PW- Permanent Wetland, SL- Shrub land, WBWater bodies, WL- Wasteland.

Overall Accuracy

[Sum of the classes present diagonally/ Total no. of classes] $\times 100$

$$
\begin{aligned}
& =[(519+1634+1147+1544+315+415+116+946+764+687) / 9003] \times 100 \\
& =8087 / 9003=89.82 \%
\end{aligned}
$$


Users accuracy

[Individual class present diagonally/ Row total of that class] $\times 100$

For example user accuracy of Barren land class:

$$
=[519 / 633] \times 100=81.9 \%
$$

Producer accuracy

[Individual class present diagonally/ Column total of that class] $\times 100$

For example producer accuracy of Barren land class:

$$
=[519 / 547] \times 100=94.9 \%
$$

Kappa coefficient

[Observed accuracy - Chance agreement]/ [1- Chance agreement]

Chance agreement $=\sum$ [ Product of row and column marginals for each class $]$

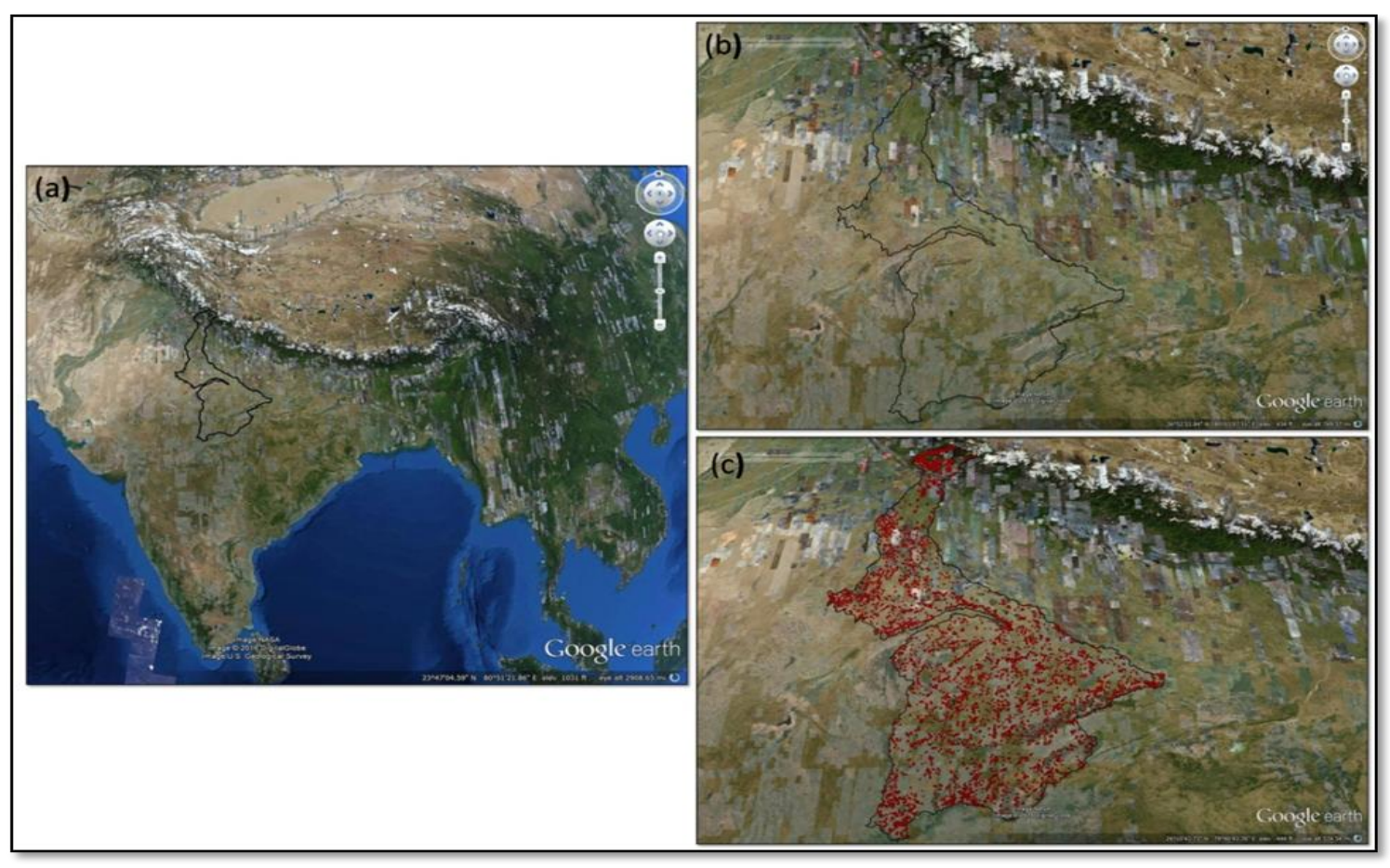

Appendix 3. (a) Yamuna basin boundary overlaid over Google earth imagery of India, (b) Extended view of Yamuna basin boundary over Google earth imagery, (c) Random points (total no. 9003) used for accuracy assessment of LULC classes overlaid above the Google earth imagery.

\section{Appendix 4. Important web resources}

http://glcf.umd.edu/data/landsat

http://data.gov.in/keywords/land-use-statistics

http://bhuvan.nrsc.gov.in

http://www.india-wris.nrsc.gov.in

http://www.indiastat.com

http://www.censusindia.gov.in 